\title{
Aprimoramento de Interfaces de Usuários de Sistemas de Informação em Saúde no Atendimento Pré-hospitalar na Ótica da Consciência Situacional
}

\section{Improvement of User Interfaces in Prehospital Healthcare Information Systems in the Perspective of Situational Awareness}

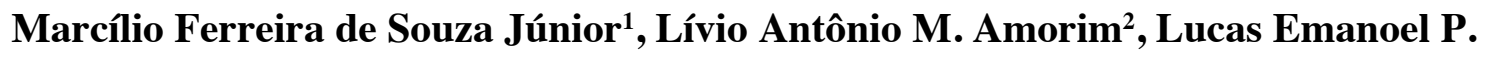
S. Santos ${ }^{2}$, Jorge Silva Correia-Neto ${ }^{3}$, Hugo Araújo Souza ${ }^{4}$

${ }^{1}$ CODAI - Universidade Federal Rural de Pernambuco (UFRPE)

São Lourenço da Mata, PE - Brasil

${ }^{2}$ Instituto Federal de Alagoas (IFAL)

Maceió, AL - Brasil

${ }^{3}$ UAEADTEC - Universidade Federal Rural de Pernambuco (UFRPE)

Recife, PE - Brasil

${ }^{4}$ Secretaria de Estado da Saúde de Alagoas (SESAU)

Maceió, AL - Brasil

marcilio.souzajr@ufrpe.br, \{livioam, lucas.eps, jorgecorreianeto\}@gmail.com, hugo.souza@saude.al.gov.br

\begin{abstract}
User interface is the gateway to the computing system and it is essential in the interaction between man and the machine, containing the functions necessary for its operation. In working environments with users under pressure, as in the SAMU 192, systems are adopted that require an effective interface for data entry in order to assist in the process of situational awareness for the user's decision making. This research undertook a qualitative analysis, from the perspective of situational consciousness, which provided improved user interfaces prototypes of the e-SUS SAMU health information system in use in the public prehospital emergency call service.
\end{abstract}

Keywords. Situational Consciousness; Health Information Systems; mobile emergency care service (SAMU 192).

Resumo. A interface do usuário é a porta de entrada do sistema computacional e é essencial na interação entre o homem e a máquina, contendo as funções necessárias para sua operação. Em ambientes de trabalho com usuários sob pressão, tal como nos atendimentos do SAMU 192, adotam-se sistemas que exigem uma interface efetiva para entrada de dados 
de modo a auxiliar no processo de consciência da situação para tomada de decisão do usuário. Assim, esta pesquisa empreendeu uma análise qualitativa, sob a ótica da consciência situacional, que forneceu protótipos aprimorados das interfaces dos usuários do sistema de informação e-SUS SAMU em uso no serviço de atendimento das chamadas de emergência pré-hospitalar.

Palavras-Chave. Consciência Situacional; Sistemas de Informação em Saúde; SAMU 192.

\section{Introdução}

A manutenção da qualidade dos dados em sistemas de informação críticos não segue um padrão devido à alta dependência dos seus objetivos, requisitos e métricas do domínio [Oliveira et al. 2015]. Por isso, garantir a consistência dos dados de sistemas em operação em ambientes críticos, como os de urgência e emergência em saúde, é um desafio, pois possíveis inconsistências nos dados podem acarretar uma situação de incompreensão da realidade modelada a partir das funcionalidades desses sistemas, afetando o modelo mental dos usuários, o que diminui a eficácia na operacionalização.

Buckley e Boulter (1997) definem o modelo mental do usuário como uma forma de representar e interpretar a realidade a partir das interfaces dos sistemas. Endsley (1995), por sua vez, cunhou este estado do modelo mental como situation awareness (SA) ou consciência situacional, definindo o nível de consciência quanto aos elementos e seus estados num ambiente, as relações entre estes elementos nesse ambiente e a projeção destes estados num futuro.

Corroborando com Endsley (1999), pontua-se que em um sistema voltado para a consciência de situação frente ao volume de informação resulta em dificuldades para interpretação do usuário que poderiam ser superados pela reformatação do design de interfaces para apresentar dados integrados, de forma a entregar a informação desejada ao usuário e alcançar um melhor entendimento da real situação.

De fato, o principal meio para alcance da SA são as Interfaces de Usuário (IU), pois são a partir delas que ocorrem a obtenção e registro das informações relevantes ao usuário-especialista que se orienta com relação à tomada de decisões com base no seu nível de SA adquirido [Oliveira et al. 2014][Velagapudi et al. 2009].

Neste cenário, o desenvolvimento de IU's que melhorem o processo de aquisição da SA são difíceis de alcançar. Por isso, várias métodos foram desenvolvidos, com destaque para o de Onal et al. (2013), que combinaram elementos gráficos de layout, como mapas virtuais e multitelas, em uma técnica denominada Situation Awareness Global Assessment Technique (SAGAT). SAGAT foi desenvolvida para avaliar SA de forma mais abrangente. Ressalta-se que o método foi utilizada por Endsley e Jones (2016) a partir de um caso de uso no cenário crítico de controle de tráfego aéreo. Outro cenário crítico possível para aplicação de SA seria no atendimento pré-hospitalar de urgência móvel, no contexto da saúde pública brasileira, pois as tecnologias de saúde têm se reveladas cruciais para a melhoria do atendimento dos cidadãos, auxiliando no processo de transformação e utilização das informações coletadas para definição de estratégias públicas de saúde [Cabral 2009][Barcellos 2008].

Um dos grandes desafios no processo de atendimento pré-hospitalar, tal como o serviço do SAMU opera, é a coleta das informações no momento da solicitação do serviço via chamada telefônica. Essas informações não apenas tem que ser obtidas no 
menor tempo possível, devido à situação de urgência médica e exigência de protocolos clínicos, mas também buscando garantir a qualidade dos dados para evitar inconsistências que prejudiquem os atendimentos. Segundo Cabral (2009), a importância desse serviço se dá pelo fato de que as vítimas de acidentes de transporte terrestre quando atendidas e encaminhadas à instituição de saúde adequada, em tempo hábil, tem maiores chances de recuperação de suas lesões.

O processo de atendimento utilizado pelo SAMU dispõe de dois tipos de equipes: (1) regulação médica, responsável pelo recebimento do chamado de urgência, coleta de informações como localização e estado da vítima, orientação nos primeiros socorros e (2) encaminhamento da segunda equipe, responsável pela intervenção médica para o local alvo do chamado, caso necessário, para prestação de atendimento clínico ou traumático. Estas duas equipes trabalham diariamente com esta situação de emergências em saúde. Cabe ressaltar neste ponto que, segundo Oliveira et al. (2014), o estresse é um dos oito maiores problemas para obtenção da SA, sendo que destes, três problemas estão relacionados diretamente aos sistemas de informação, sendo eles: excesso de dados, destaques mal inseridos nas interfaces e complexidade do sistema.

Recentemente, a demanda por prestação de atendimento pré-hospitalar tem aumentado no SUS. Essa demanda acarretou num aumento na quantidade de informações a serem gerenciadas e é um dos problemas que afetam a consciência dos usuários dos sistemas no entendimento das variadas situações de ocorrências na Central de Regulação do SAMU. A dificuldade em conciliar agilidade na entrada dos dados no sistema de informação aliada a garantia da qualidade dos dados informados, durante o atendimento de uma ocorrência de emergência, é um desafio, pois, por vezes, certas quantidades de dados em campos necessários do sistema para a compreensão dos atendimentos em si pela equipe médica acabam não sendo informados ou não solicitados ao paciente devido ao curto tempo do atendimento. Os dados, a priori descartados, são essenciais na aquisição da SA por parte do usuário do sistema, tanto em curto prazo, quando o atendente deve tomar uma série de decisões durante o telefonema ou quando o médico regulador precisará decidir qual o tipo de unidade móvel deveria ser enviada para o local da ocorrência, quanto no longo prazo, no planejamento e melhoria do serviço por parte da gestão.

Com a problemática assim descrita, lança-se a seguinte questão de pesquisa: como as interfaces de usuário para entrada de dados em um sistema crítico de atendimento pré-hospitalar, tal como o e-SUS SAMU, podem ser aprimoradas caso fossem orientadas pela consciência situacional dos operadores?

Neste cenário, o presente trabalho situa o processo de atendimento pré-hospitalar do SAMU como um ambiente de usuários sob pressão, pois os atendentes e operadores do sistema lidam diretamente com a manutenção de vidas humanas. Essa pressão pode resultar no acometimento de estresse por parte do operador do SAMU e, assim, comprometer seu processo de aquisição da SA junto às interfaces do sistema de informação em saúde. Sendo assim, considerando a área de urgência e emergência como um ambiente crítico para os usuários de sistemas de informação, a presente pesquisa visou analisar as IU's do sistema e-SUS SAMU na ótica da consciência situacional. Este sistema encontra-se em operação nas centrais de regulação do Serviço de Atendimento Móvel de Urgência (SAMU), suportando o gerenciamento das informações oriundas das chamadas telefônicas 192 de solicitação de atendimento pré-hospitalar. Como resultado, 
foram desenvolvidos protótipos aprimorados de interface de usuário orientada a SA com a validação das percepções da equipe do SAMU.

$\mathrm{O}$ artigo foi organizado do seguinte modo. A seção 2 discute o conceito da consciência situacional e a sua relação com as interfaces de usuários de sistemas de informação. A seção 3 descreve o proceder metodológico da pesquisa, delineado em quatro etapas. Já a seção 4 discute os resultados alcançados e os protótipos de interfaces desenvolvidos. Por fim, a seção 5 apresenta as conclusões e os trabalhos futuros.

\section{Consciência Situacional e as Interfaces de Sistemas de Informação}

O conceito de situation awareness (SA) ou consciência situacional define um estado em que a pessoa está ciente daquilo que acontece ou existe à sua volta, das relações entre estes elementos existentes, e projeta uma situação futura. Este conceito surgiu a partir do estudo da psicologia no setor de aviação, no qual se buscava descrever o ambiente que envolvia o piloto de uma aeronave para melhorar seu desempenho através da previsão de estados futuros do ambiente.

Tal conceito passou a ser aplicado em diversos outros domínios que envolvem ambientes que mudam dinamicamente e que esteja inserido um operador responsável pela manutenção ou obtenção de estados ou metas particulares [Durso e Gronlund 1999], tais como: militarismo, sistemas táticos, educação, manutenção de equipamentos, previsão do tempo, refinarias, operações espaciais e medicina [Pew e Mavor 1998] [Baratto 2011][Silva et al. 2012].

Endsley (1999), por sua vez, define a consciência situacional como o entendimento dos componentes do ambiente dentro de um espaço e tempo, o significado que eles representam e a projeção da situação em um futuro próximo, subdividida em três níveis: a percepção dos elementos do ambiente, a compreensão da situação corrente e a projeção da condição futura. A Figura 1 ilustra um modelo detalhado da SA.

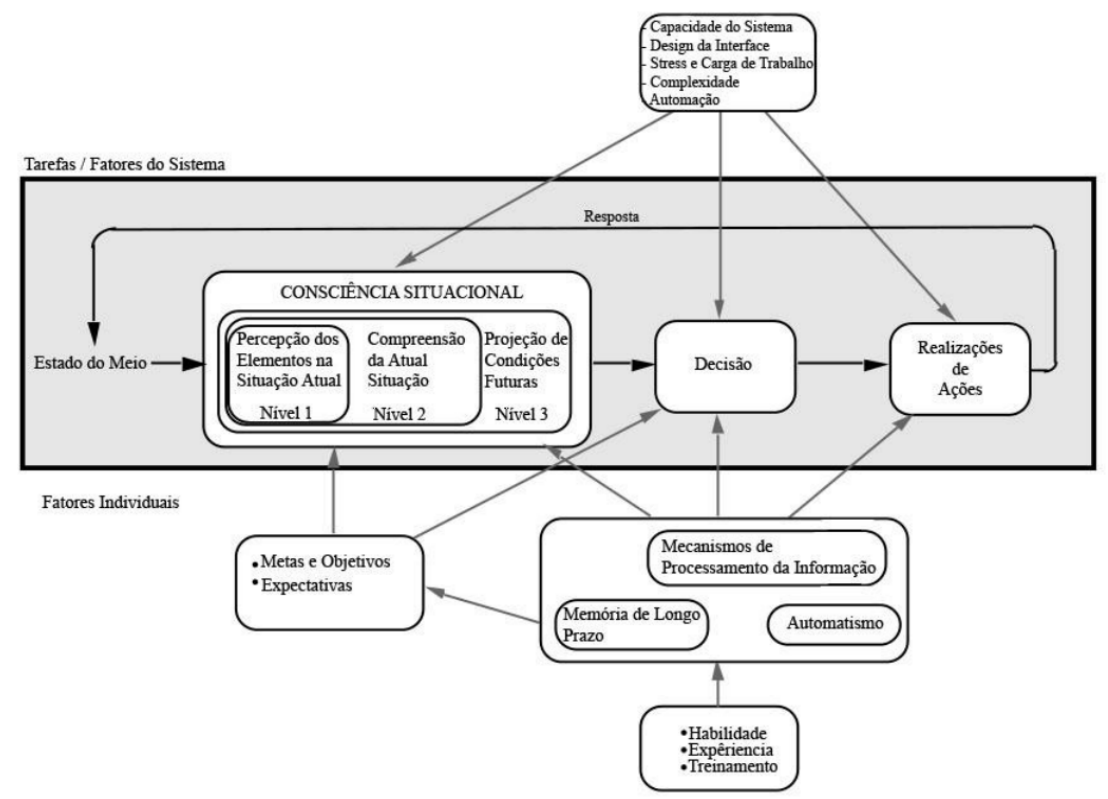

Figura 1 - Modelo de alto nível de consciência situacional

Fonte: Endsley (1999) 
Segundo o modelo, no primeiro nível da SA ocorre a identificação dos principais elementos do ambiente que irão servir para definir a situação, focando os mais relevantes [Pew e Mavor 1998]. Conforme Endsley (1995), nesta fase de percepção, um piloto de avião, por exemplo, buscaria elementos como montanhas, outras aeronaves, luzes de aviso etc, já um motorista deveria estar atento à existência e localização de outros veículos, obstáculos etc, bem como da maneira de dirigir de outros motoristas. Desta forma, a percepção do ambiente é importante para diminuir a probabilidade de formar uma imagem errada do mesmo, haja vista ser esta uma das principais causas de erros humanos [Silva et al. 2012].

O nível 2 da SA envolve a compreensão. Observa-se neste nível o significado dos elementos em conjunto, ou seja, a relevância existente entre eles para que apoiem a tomada de decisão, visualizando uma imagem global do ambiente [Endsley 1995]. Como exemplo ilustrativo, no cenário que um médico anestesista durante um procedimento cirúrgico é avisado pelos instrumentos auxiliares que os batimentos do coração do paciente estão aumentando e então em um curto espaço do tempo deve determinar quão sério é o problema, combinando com outras informações, para decidir qual medicamento poderia utilizar para fazer o paciente retornar ao seu estado normal sem afetá-lo.

No nível final, denominado projeção, baseando-se no ambiente e nas suas relações, busca-se efetuar a previsão de eventos futuros em um curto prazo, planejando, avaliando e antecipando as opções existentes para que a tomada de decisão seja a mais exata possível [Pew e Mavor 1998]. Endsley (1995) exemplifica que um motorista necessita detectar possíveis futuras colisões para que possa agir de forma efetiva. Da mesma forma que um operador de manufatura precisa predizer futuros gargalos por máquinas quebradas para conseguir manter seu cronograma.

A passagem por esses três níveis corresponde ao alcance da consciência situacional daquele estágio, visto que ao tomar consciência da situação específica, o ator efetua a tomada de decisão e age. Este processo provoca uma rearrumação dos elementos à volta, sendo necessário recomeçar novamente o processo.

Ressalta-se que alguns fatores podem influenciar o processo de aquisição de SA, tais como: gargalo de atenção, ou seja, a dificuldade em se prestar atenção a várias informações; limitação de memória, a parte da memória utilizada para formar a visualização global do ambiente; fatores de estresse, como ansiedade e cansaço que prejudicam a cognição; excesso de dados, referindo-se a rápida e constante atualização de dados; informações mal inseridas ou interpretadas; complexidade do sistema; modelo mental incorreto, baseado em experiências de situações similares, mas que não condizem com a atual e automação, que pode tornar o usuário dependente do sistema [Oliveira et al. 2015].

Diante do exposto, dizer que alguém é capaz de adquirir SA é reconhecer que ela tem entendimento e conhecimento para realizar eficientemente as atividades a ela atribuídas, porém a construção da consciência situacional é algo adquirido de acordo com a experiência que o indivíduo obtém ao passar pelas mais diversas situações. Um profissional novato ou inexperiente em um determinado domínio, provavelmente não irá tomar decisões tão exatas quanto um mais experiente e envolvido em diversas situações, portanto, SA necessita de desenvolvimento. [Onal, Craddock e Endsley 2013][Silva et al. 2012]. 
A interface do usuário é a porta de entrada do sistema computacional e é essencial na interação entre o homem e a máquina, contendo as funções e ferramentas necessárias para o usuário.

Os ambientes críticos, em especial, utilizam-se geralmente de sistemas de apoio à decisão, que exigem uma interface de usuário efetiva para entrada de dados de modo a manter a interação com o sistema e auxiliar no processo de consciência da situação para tomada de decisão por parte do usuário.

É nesse contexto que a SA se alia às interfaces. Pois, as interfaces dos sistemas de apoio à decisão em ambientes críticos deveriam direcionar o usuário nas etapas de avaliação das situações e cenários possíveis através da visualização adequada das informações na tela. Estas informações servem para auxiliar o usuário na aquisição de um nível situacional no contexto da tomada de decisão [Oliveira et al. 2015].

Portanto, a interface do usuário influenciará o nível de consciência situacional a ser adquirido por usuários dos ambientes críticos, tal como no domínio pré-hospitralar que este trabalho se propôs a pesquisar. A interface do usuário em um ambiente de gerenciamento de atendimentos das ocorrências de emergência exige que o usuário se situe no cenário e observe a situação, deliberando o que solicitar ao sistema, para depois decidir se necessita de mais interação ou se já pode tomar a decisão peculiar àquele cenário.

Assim, nos sistemas orientados à consciência de situação é necessário que a interface forneça ao usuário o que está acontecendo em um determinado ambiente, visto que as informações passadas pelo sistema irão influenciar a aquisição, entendimento e projeção do operador sobre determinado caso, podendo comprometer ou não a tomada de decisão.

Algumas interfaces orientadas a SA automatizam o papel dos usuários, sendo o ator humano não somente consumidor da informação, mas também produtor dela, a fim de melhorar a resposta final do mesmo, gerando necessidade de estudo quanto às consequências da intervenção na construção da consciência situacional. Em outras abordagens, diferentemente, apesar de incluírem o homem como ator no processo, não permitem ao mesmo o acesso a todo ambiente de manipulação das informações, dando as oportunidades de interação apenas a cada nível de avaliação [Oliveira et al. 2015].

Com relação aos trabalhos correlatos, foram encontrados apenas estudos de domínios que não abrangiam a saúde, principalmente, a saúde pública, tal como abordado na presente pesquisa. Ferreira (2014) também propôs interfaces para usuários modeladas graficamente, utilizando moqups, onde se obteve a estrutura da IU juntamente com seus respectivos componentes de controle e a especificação dos aspectos que influenciavam a SA. No entanto, o domínio estudado foi o de um sistema de tomada de decisão militar para monitoramento de crimes de roubo. Da mesma forma, Nazir et al. (2002) destacaram a importância de se considerar SA em sistemas de operação de controle em processos críticos industriais, explicando as consequências de se enfrentar situações anormais do sistema a depender da consciência e da comunicação efetiva e compartilhada entre os usuários. Já Oliveira et al. (2015) demonstraram como incluir IU orientada a SA alinhado ao processo de um sistema de emergência adotando um cenário crítico de um evento de roubo para demonstrar a aplicabilidade da abordagem proposta. 


\section{Método}

A presente pesquisa foi delineada seguindo uma abordagem qualitativa [Orlikowski e Baroudi 1991]. A triangulação foi adotada visando minimizar possíveis vieses dos pesquisadores. Portanto, buscaram-se pelo menos três fontes para cada dado coletado no estudo. Assim, usou-se mais de uma técnica de coleta de dados, a saber: documental (acesso aos manuais e guias do usuário do Sistema e-SUS-SAMU), entrevistas semiestruturadas (junto aos sujeitos da pesquisa) e observação não participante (in loco no ambiente de trabalho dos usuários). Ainda, o uso de múltiplos pesquisadores foi também adotado na codificação múltipla para a análise dos dados, maximizando a validade dos resultados.

Estruturada em quatro etapas, o percurso metodológico ocorreu a partir do (i) aprofundamento do conhecimento sobre a temática da consciência situacional (SA) e do domínio estudado (SAMU 192), (ii) análise das Interfaces de Usuário (IU) do sistema eSUS SAMU na versão 1.4, desenvolvido pelo DATASUS e implantado na unidade de Maceió-AL pelo Ministério da Saúde, englobando o levantamento dos objetivos e dos requisitos necessários para alcançar a SA dos usuários, (iii) desenvolvimento de protótipos de IU para o e-SUS SAMU, orientados a SA, e por último, (iv) validação dos protótipos através de entrevistas baseadas na compreensão da melhoria da situação dos atendimentos na unidade de Maceió. Os fatores oriundos da SA considerados na avaliação das interfaces do Sistema foram: gargalo de atenção, limitação de memória, stress dos usuários, excesso de dados, saliências mal inseridas e complexidade do sistema [Oliveira et al. 2015].

$\mathrm{Na}$ primeira etapa da pesquisa foram realizadas pesquisas bibliográficas para aprofundar o conhecimento sobre a consciência situacional (SA), bem como pesquisas de campo para adentrar no domínio do SAMU. Nesta etapa foi também planejada a fase de coleta de dados, que ocorreu a partir de entrevistas semiestruturadas seguindo um roteiro com perguntas abertas, direcionadas a cada sujeito da pesquisa membro da equipe de regulação médica. As entrevistas foram conduzidas seguindo a metodologia Goal-directed Task Analysis (GDTA) [Endsley e Jones 2016]. A primeira entrevista foi efetuada com 03 (três) sujeitos: um Médico Regulador (MR), um Técnico Auxiliar de Regulação Médica (TARM) e um Rádio Operador (RO). Os dois últimos, a depender da escala de trabalho, exerciam a função de TARM ou de RO. Para facilitar a compreensão, este trabalho denomina como "Reguladores" os sujeitos com perfil de médico, "Intervencionistas" aqueles que possuem autonomia para direcionar procedimentos durante o atendimento e "Assistentes de Regulação", que eram TARM ou RO (responsáveis por dar suporte aos reguladores). A escolha dos entrevistados teve como base a função de trabalho exercido e o nível do seu conhecimento do sistema eSUS SAMU. Os Intervencionistas faziam parte da equipe médica que circulavam nas unidades veiculares de emergência e, por isso, não possuíam acesso ao sistema no processo de atendimento de uma ocorrência e não foram contemplados nas entrevistas.

Para a segunda etapa da pesquisa foram cedidas pela direção do SAMU as interfaces principais do sistema e-SUS, em formato de imagens, além dos documentos com o manual de operação do software e das funcionalidades disponíveis para execução do processo de trabalho. Nesta etapa também foram realizadas observações in loco com o intuito de alcançar uma avaliação mais aprimorada do uso das interfaces do sistema eSUS SAMU e dos processos da organização. Como método de coleta de dados, na 
observação não participante, o pesquisador não está diretamente envolvido na situação a se observar, isto é, não interage nem se envolve intencionalmente com o objeto da observação [Abib, Hoppen e Hayashi-Júnior 2013].

$\mathrm{Na}$ terceira etapa, a partir dos dados coletados na etapa anterior, foram elaborados protótipos de interfaces de usuário. Utilizou-se a ferramenta Pencil versão 2.0.5. Os protótipos orientados a SA foram baseados nas telas fornecidas do sistema eSUS SAMU, a saber: controle de frota, solicitação de chamada, registro de paciente, avaliação de paciente, avaliação e orientação médica, conduta médica e conclusão da ocorrência, que contemplam as visões dos usuários: TARM, Médico Regulador e Rádio Operador.

Por fim, uma última etapa de validação ocorreu com o retorno dos pesquisadores à central de regulação do SAMU para realização de novas entrevistas e então verificar junto aos sujeitos da pesquisa as sugestões de melhorias na interface proposta. Optou-se por selecionar 03 (três) sujeitos diferentes da primeira etapa, utilizando outro instrumento de coleta baseado em questões sobre melhoria da SA que foram refletidas nas interfaces prototipadas. Totalizaram-se, portanto, 06 (seis) sujeitos entrevistados na primeira e na quarta etapas, o que se mostrou suficiente para atingir a saturação e os objetivos propostos.

\section{Resultados e discussões}

Esta seção apresenta os resultados das análises das interfaces do sistema e-SUS-SAMU, sendo operacionalizado pelo corpo de atendimento da unidade situada em Maceió-AL. As interfaces discutidas aqui não representam a totalidade do sistema, apenas aquelas que fizeram parte da pesquisa, mas que concentram a parte mais relevante das telas para o atendimento das ocorrências dos chamados 192.

\subsection{Análise das interfaces do Sistema e-SUS SAMU}

O e-SUS-SAMU tem sua interface baseada em abas que representam seções dentro do sistema. Sua organização base consiste em uma tela com orientação em formato paisagem contendo em seu topo os logos da SAMU 192 e a região/cidade para a qual o sistema está sendo utilizado. Ainda no topo existe um relógio e data atualizados, que fornecem as informações temporais a respeito do atendimento, um cronômetro que inicia contagem a cada novo atendimento e mostra em tempo real a duração (tempo resposta), cuja funcionalidade é desconhecida pelos usuários e sua descrição inexiste nos manuais disponíveis na página do DATASUS. Também são disponibilizadas outras funcionalidades, como um chat para permitir conversação, uma pesquisa para localizar alguma ocorrência, alteração de senha para permitir a troca de senha do usuário e um link para encerrar a sessão do usuário. Abaixo do topo há duas caixas onde estão divididas as seções em formato de abas. Um dos pontos relatados como positivos pela equipe de regulação foi a disposição destas abas, organizadas da esquerda para direita e seguindo a ordem de atendimento, o que facilita o percepção do posicionamento dos dados para cada fase do processo de atendimento.

$\mathrm{Na}$ interface Solicitante são inseridas as informações iniciais a respeito da ocorrência atendida pelo SAMU, que subdivide-se em quatro quadros, conforme ilustrado pela Figura 2. Também é informado o identificador gerado pelo sistema ao ser inserido o número do telefone de contato para dar início do atendimento. O primeiro 
quadro possui os campos Telefone da Ocorrência, Solicitante, Motivo/Queixa e Apelido de Ocorrência. O segundo quadro corresponde às informações sobre a "localização da ocorrência" e todos os seus dados são preenchidos pelo atendente. Já o terceiro quadro recebe as informações sobre a "Classificação da ocorrência" e são preenchidos pelos médicos reguladores. Ao clicar no botão Avaliação/Orientação, o médico regulador tem acesso a tela de Avaliação/Orientação Médica. O quarto quadro possui uma caixa para mensagens a serem visualizadas pelo médico ao receber um encaminhamento direto. Há ainda os botões de encerramento, caso a solicitação seja cancelada pelo solicitante, em fila, onde a ficha aguarda disponibilidade de apoio de outros órgãos como polícia ou Corpo de Bombeiros para dar prosseguimento ao atendimento.

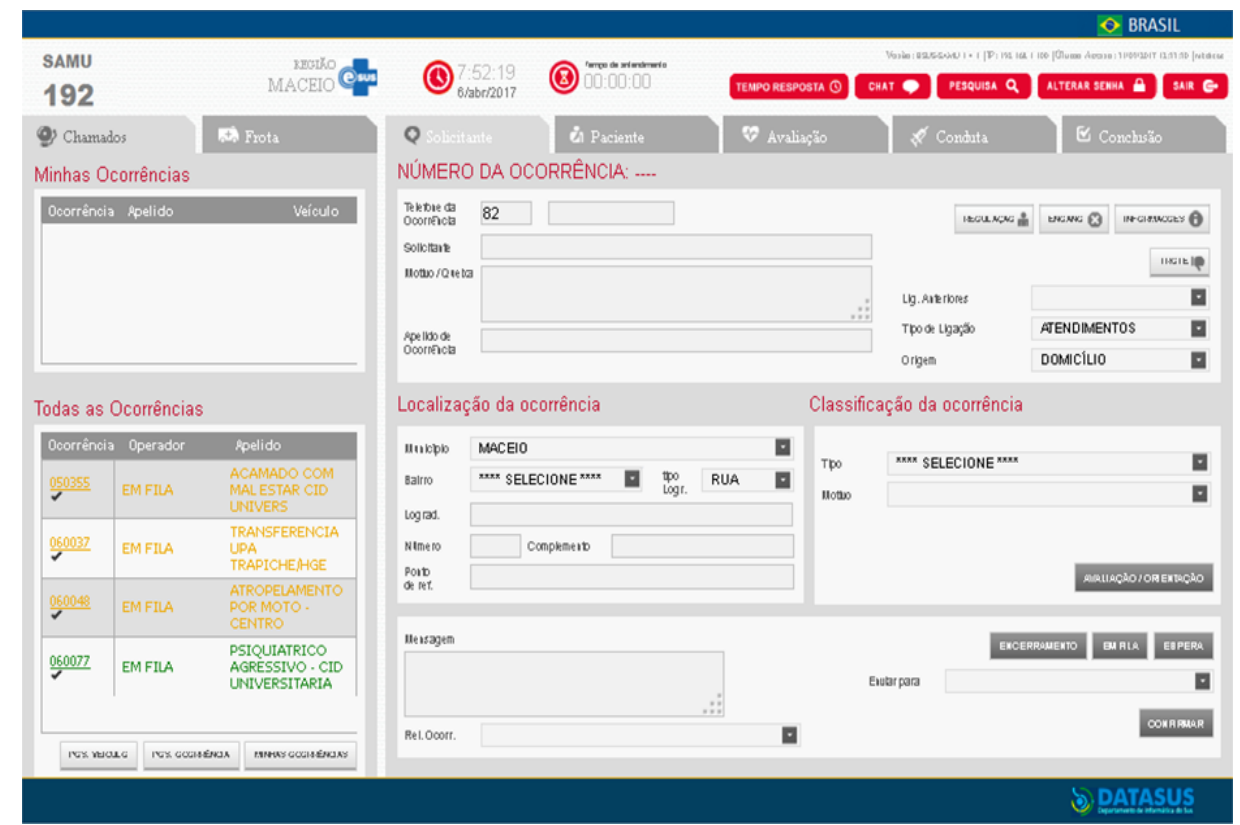

Figura 2 - Interface Solicitante do e-SUS SAMU

É na interface Paciente onde são inseridos os dados relativos ao(s) paciente(s) da ocorrência cadastrada, conforme ilustra a Figura abaixo. A tela acima contém dois quadros, o primeiro destinado aos dados a serem inseridos do(s) paciente(s) e o segundo tem seu funcionamento igual ao quarto quadro descrito na Tela do Solicitante, exceto pela funcionalidade de relacionar a ficha atual a outra já existente. $\mathrm{O}$ primeiro quadro possui o botão "incluir Paciente" e os seguintes campos: Paciente, Classificação do Paciente (Criança, Adulto, Idoso, etc), Idade, Gênero, Nome Completo, Número Documento, Órgão Emissor (SSP, SEDS, etc), CNS, CPF, Município (todos os municípios do Estado de Alagoas), Bairro, Tipo Logradouro (Rua, Avenida, Travessa, etc), Logradouro, CEP, Número e Complemento. Tais dados são preenchidos pelo atendente após o cadastramento da ocorrência para que os mesmos sejam acessíveis pelo médico regulador designado ao atendimento do caso. Uma tela sobreposta à interface principal é exibida quando acessada através do botão "AvaliaçãolOrientação" da Aba Solicitante, que dividi-se em cinco quadros. Nessa tela o médico registra suas avaliações iniciais e comunica ao Rádio Operador a respeito de qual tipo de unidade(s) e para qual(is) risco(s) ela(s) devem estar preparadas ao serem encaminhadas. 


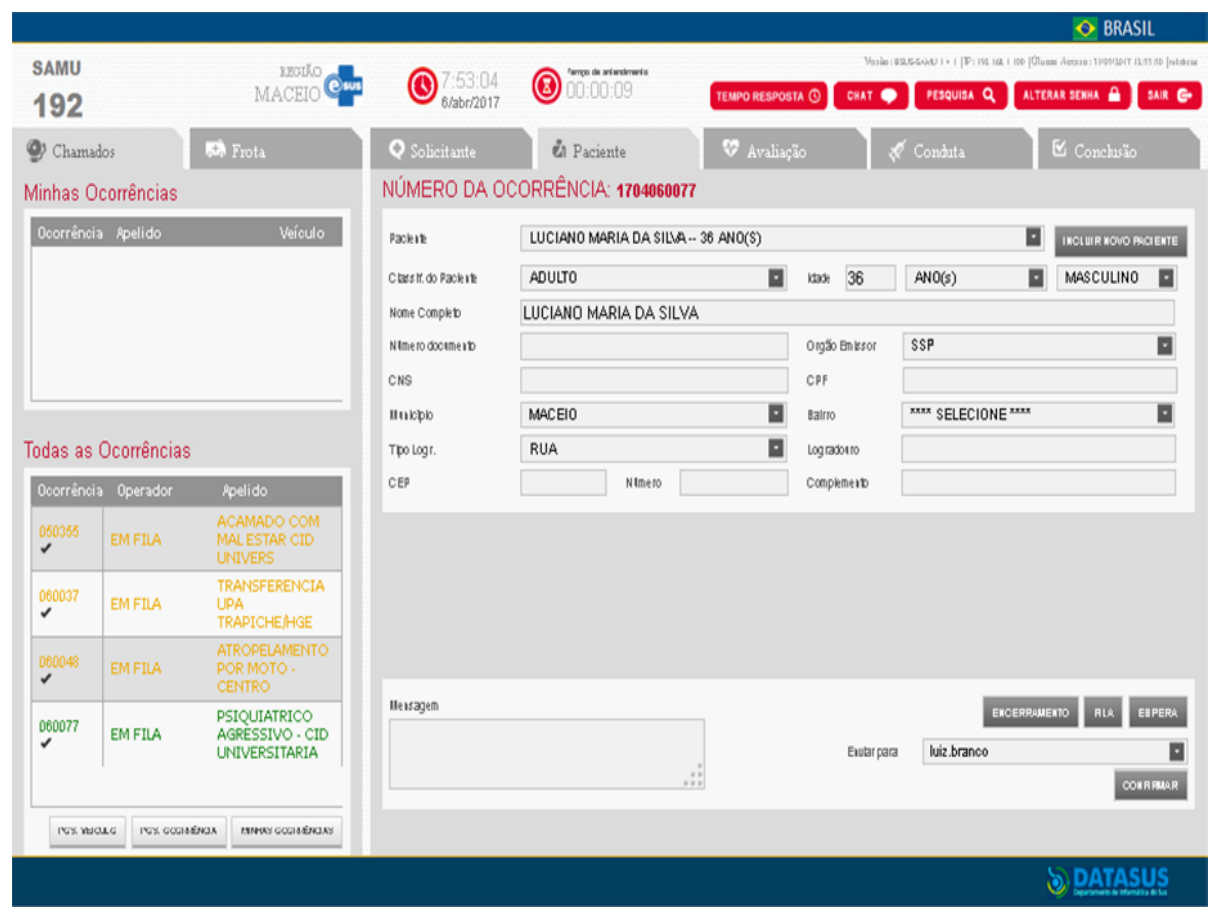

Figura 3 - Interface Paciente atual

\subsection{Mapeamento dos níveis de consciência situacional dos usuários do SAMU}

No primeiro contato com a equipe do SAMU no local do estudo foram coletadas informações referentes às atividades e decisões dos usuários que faziam parte do processo de atendimento das chamadas de emergência. Este levantamento seguiu a metodologia proposta por Endsley e Jones (2016), que visou obter informações sobre o processo interno do serviço de atendimento de urgência, conforme descrito na seção de metodologia.

O método GDTA orientou no mapeamento das tarefas executadas pela equipe de regulação, composta pelo Técnico Auxiliar de Regulação Médica (TARM), Médico Regulador e Rádio Operador. A partir das entrevistas junto aos usuários, foi possível gerar as informações para os três níveis de SA preconizados na literatura. Tais achados estão listados no quadro a seguir. O quadro foi elaborado para possibilitar uma melhor visualização e leitura das informações, compondo dados primordiais para analisar a consciência situacional dos usuários na execução de suas atividades e nas dificuldades de utilização do sistema. 


\begin{tabular}{|c|c|c|c|}
\hline - & SA Nível 1 & SA Nível 2 & SA Nível 3 \\
\hline Usuários & $\begin{array}{l}\text { Informações necessárias } \\
\text { para estimular a percepção } \\
\text { do usuário }\end{array}$ & $\begin{array}{l}\text { Informações que indicam } \\
\text { as relações entre os } \\
\text { elementos percebidos para } \\
\text { aguçar a compreensão do } \\
\text { usuário. }\end{array}$ & $\begin{array}{l}\text { Informações que indicam a } \\
\text { evolução dos eventos e que } \\
\text { possibilitam projetar } \\
\text { estados futuros. }\end{array}$ \\
\hline TARM & $\begin{array}{l}\text { 1.1 Condições básicas da(s) } \\
\text { vítima(s): ferida, } \\
\text { desacordada, sonolenta, com } \\
\text { dores, etc; } \\
1.2 \text { Localização da(s) } \\
\text { vítima(s): logradouro formal } \\
\text { e descrição informal da } \\
\text { localização; } \\
1.3 \text { Identificação do } \\
\text { solicitante: solicitante é a } \\
\text { vítima, nome completo, } \\
\text { telefone, origem da ligação, } \\
\text { tipo de ligação, etc; } \\
\text { 1.4 Cronometragem do } \\
\text { atendimento: } \\
\text { tempo decorrido desde o } \\
\text { momento do atendimento até } \\
\text { seu encaminhamento para o } \\
\text { médico regulador ou } \\
\text { encerramento; }\end{array}$ & $\begin{array}{l}2.1 \text { Trata-se de um trote: } \\
\text { Informações incoerentes ou } \\
\text { outros sinais; } \\
2.2 \text { Outras chamadas para a } \\
\text { mesma(s) vítima(s): Outro } \\
\text { solicitante reportou o mesmo } \\
\text { acidente ou mal clínico; } \\
2.3 \text { É competência da SAMU } \\
\text { atender ao chamado de } \\
\text { emergência: características } \\
\text { sobre o tipo de atendimento } \\
\text { preenchem os requisitos e } \\
\text { assim transferir a ligação } \\
\text { para o Médico Regulador; } \\
\text { 2.4 Identificação descritiva } \\
\text { do chamado (apelido): } \\
\text { usando palavras chave para } \\
\text { identificar o chamado; }\end{array}$ & $\begin{array}{l}3.1 \text { Número alto de trotes } \\
\text { recebidos nos últimos } \\
\text { minutos: indivíduo(os) } \\
\text { pode }(\mathrm{m}) \text { estar insistindo na } \\
\text { tentativa de trote ou o } \\
\text { número já foi registrado no } \\
\text { sistema com muitos trotes. }\end{array}$ \\
\hline $\begin{array}{l}\text { Médico } \\
\text { Regulador }\end{array}$ & $\begin{array}{l}1.1 \text { Condições específicas } \\
\text { da(s) vítima(s): Lesões, } \\
\text { perfurações, sintomas, etc; } \\
1.2 \text { Circunstâncias que } \\
\text { levaram a(s) vítima(s) as } \\
\text { condições informadas: } \\
\text { acidente ou mal clínico; } \\
\text { 1.3 Horário em que ocorreu o } \\
\text { acidente ou que se iniciaram } \\
\text { os sintomas do mal clínico; }\end{array}$ & $\begin{array}{l}\text { 2.1 Tempo decorrido entre o } \\
\text { horário que ocorreu o } \\
\text { acidente ou mal clínico e o } \\
\text { solicitação chegar ao } \\
\text { conhecimento do Médico } \\
\text { Atendente; } \\
2.2 \text { Timer em tempo real do } \\
\text { atendimento; } \\
\text { 2.3 Grau de estado da vítima: } \\
\text { Gravíssimo, Grave, etc. de } \\
\text { acordo com regulamentação } \\
\text { ou literatura existente; } \\
\text { 2.4 Que unidade de } \\
\text { atendimento móvel } \\
\text { encaminhar: USB, USA, etc; } \\
2.5 \text { Tempo médio até a } \\
\text { chegada da unidade ao local; }\end{array}$ & $\begin{array}{l}\text { 1.1 Vítima muito tempo sem } \\
\text { atendimento: quadro da } \\
\text { vítima pode se agravar em } \\
\text { futuro próximo; } \\
1.2 \text { Sintomas indicam mal } \\
\text { clínico grave em processo de } \\
\text { evolução: A vítima corre } \\
\text { risco de vida ou de graves } \\
\text { sequelas. }\end{array}$ \\
\hline
\end{tabular}




\begin{tabular}{|c|c|c|c|}
\hline $\begin{array}{l}\text { Rádio } \\
\text { Operador }\end{array}$ & $\begin{array}{l}\text { 1.1 Qual tipo de unidade de } \\
\text { socorro enviar: USB, USA, } \\
\text { etc; } \\
\text { 1.2 Qual localização da } \\
\text { vítima: logradouro completo } \\
\text { e descrição informal da } \\
\text { localização; } \\
\text { 1.3 Localização das unidades } \\
\text { de atendimento: Na base, } \\
\text { seguindo para atendimento, } \\
\text { transportando vítima para } \\
\text { instituição médica ou } \\
\text { retornando para base; } \\
\text { 1.4 Condições do trânsito: } \\
\text { informações } \\
\text { congestionamento, obras ou } \\
\text { desvios nas vias da cidade. }\end{array}$ & $\begin{array}{l}\text { 2.1 Unidades em situação de: } \\
\text { em atendimento ou } \\
\text { disponíveis } \\
\text { encaminhamento; } \\
\text { 2.2 Rotas: sugestão de rotas } \\
\text { otimizadas. }\end{array}$ & $\begin{array}{l}\text { 3.1 Período de atendimento } \\
\text { em horário de tráfego mais } \\
\text { intenso: a chegada da } \\
\text { unidade de atendimento pode } \\
\text { demorar mais tempo que o } \\
\text { normal; } \\
\text { 3.2 Local de atendimento de } \\
\text { difícil acesso: equipe terá } \\
\text { que fazer parte do trajeto fora } \\
\text { da unidade de atendimento. }\end{array}$ \\
\hline
\end{tabular}

\section{Quadro 1 - Níveis de consciência das tarefas dos usuários no atendimento pré- hospitalar Fonte: Dados da pesquisa}

$\mathrm{O}$ quadro 2 detalha os principais requisitos relativos à interface do sistema eSUS-SAMU levantados pelos usuários entrevistados, considerando os níveis de SA almejados pela pesquisa. Este detalhamento foi imprescindível para a proposta de protótipos de interfaces orientadas a SA que serão apresentados na seção seguinte.

\section{TARM - Atendimento Telefônico}

1 - Percepção a respeito da possibilidade de trote para números telefônicos já cadastrados na base do SAMU.

2 - Quantidade de caracteres para digitação de referências para localização da ocorrência (orientado mínimo de duas) no campo "Ponto de Ref." insuficiente.

3 - Possível repetição de digitação dos mesmos dados do campo Solicitante na aba Solicitante no campo Paciente na aba Paciente, quando solicitante e paciente se tratarem do mesmo indivíduo.

4 - Ausência de ferramenta de mapas para melhor compreensão a respeito da localização da ocorrência.

\section{MR - Médico Regulador}

1 - Acesso fácil a localização em tempo real das unidade de atendimento indisponível.

2 - Digitação de avaliações, históricos e observações é cansativo e consome muito tempo.

3 - Dificuldade para consultar quais unidades foram encaminhadas para um atendimento.

4 - Necessidade de retornar ou mudar de abas.

\section{RO - Radio Operador}


1 - Acesso fácil a localização em tempo real das unidade de atendimento indisponível.

\section{Quadro 2 - Requisitos relativos à interface do sistema e-SUS-SAMU Fonte: Dados da pesquisa.}

\subsection{Interfaces aprimoradas orientadas à consciência situacional}

Nesta seção são apresentadas os protótipos de interfaces de usuário que consideraram o aprimoramento da consciência situacional no uso do Sistema e-SUS SAMU. Para a construção das telas foi utilizada a ferramenta Pencil Project 2.0.5.

A Figura abaixo ilustra o protótipo da interface Solicitante. As letras em destaque na Figura indicam os pontos de melhoria que foram propostos, considerando as telas originais do sistema e-SUS SAMU (apresentadas na subseção 4.1) e as dificuldades dos usuários na execução das suas respectivas tarefas no uso do sistema e os requisitos desejados para novas funcionalidades (apresentados na subseção 4.2).

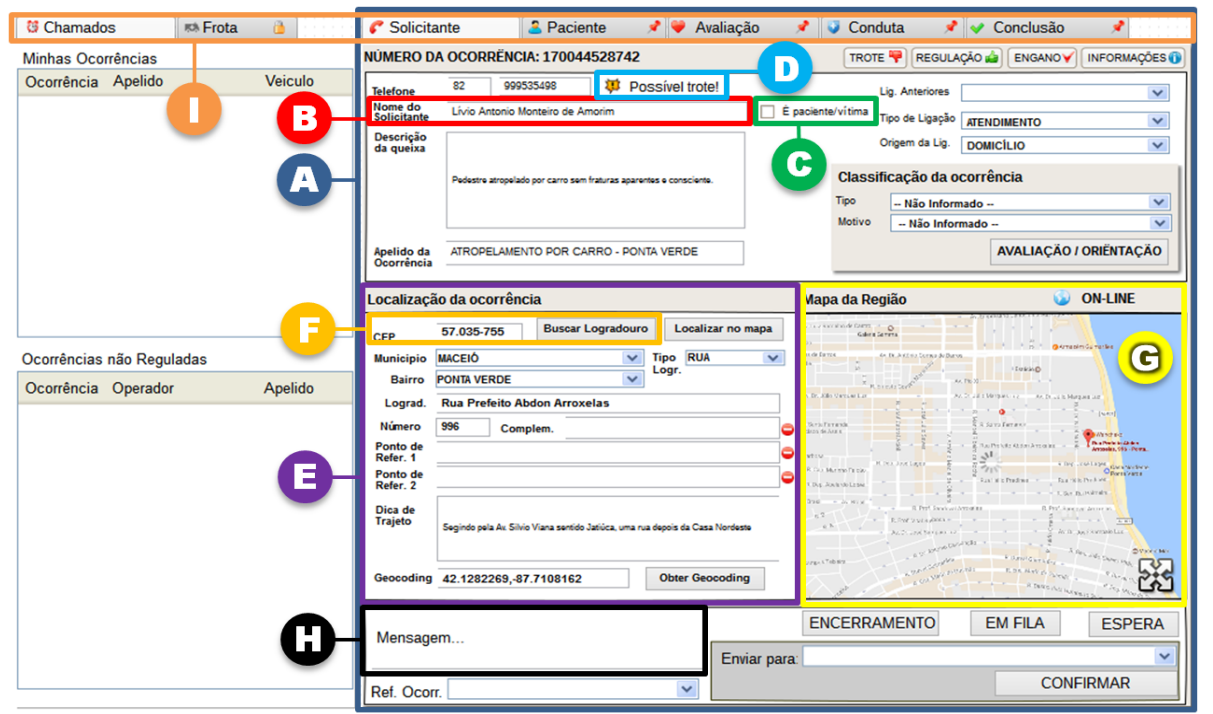

Figura 4 - Interface Solicitante orientada à Consciência Situacional

As propostas apresentadas para melhorias dessa tela, visando à consciência situacional, foram as seguintes:

A. Reorganização dos quadros para melhor aproveitamento do espaço da tela a fim de acomodar novos recursos;

B. Alteração do nome do campo Nome para Nome do Solicitante;

C. Checkbox ao lado do campo Nome do Solicitante, que ao ser marcado indica que o solicitante também é um paciente e seu nome será automaticamente preenchido no campo Paciente na aba Paciente, eliminando uma nova digitação ou a necessidade de copiar este dado manualmente;

D. Criação de alertas baseados em listas (Black List, White List) dos números telefônicos para auxiliar a distinção dos tipos de chamada, como chamadas repetidas, nova chamada, trotes, destacando a probabilidade de trote para números recorrentemente identificados previamente como trotes; 
E. Priorização na solicitação e inserção do CEP e acréscimo de campos para auxiliar a localização da ocorrência, sendo eles: criação de um segundo campo para ponto de referência e criação de um campo para dica de trajeto até o local da ocorrência e outro campo para ser inserido a geolocalização;

F. Em ocorrências que o CEP for informado, a busca dos dados do logradouro será feita na base de dados dos correios e auto preenchidos nos respectivos campos em Localização da ocorrência;

G. Pesquisa em plataforma de mapas integrada a interface para possibilitar obtenção de mais informações, como no caso do Geocoding;

H. A guia de abas possui marcadores identificados com ícones no lado direito, sendo eles:

a. Um pino vermelho, informando que essa aba ainda não foi acessada durante o processo de atendimento e em caso de reabertura de uma ficha que estava em estado de espera pelo mesmo Médico Regulador que a regulou antes da entrada na fila, este já será redirecionado para a última aba utilizada e em caso de um novo Médico Regular assumir o atendimento, este será redirecionado para a primeira aba do processo e todas as abas receberam novamente a marcação do pino vermelho;

b. Um cadeado, informando que o operador não possui acesso à aba em questão.

Já o protótipo da interface Paciente é ilustrado na Figura 5. As melhorias da interface são apresentadas para cada letra destacada na Figura logo em seguida.

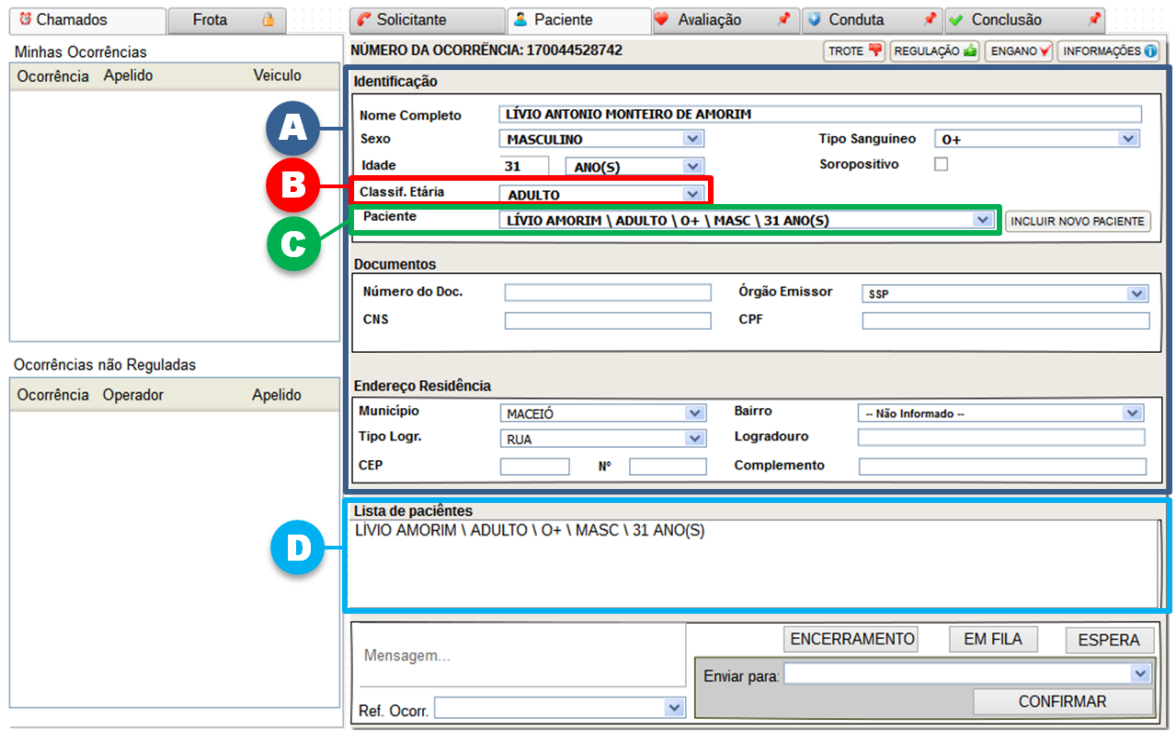

Figura 5 - Interface Paciente orientada à Consciência Situacional

A. Reorganização dos quadros e separação de campos por tipo de conteúdo (Identificação, Documentos, Endereço Residência) para uma melhor visualização e entendimento do dados;

B. O campo Classif. Etária é automaticamente preenchido com base na idade, exata ou aproximada, informada, economizando tempo e esforço mental; 
C. O campo Paciente é automaticamente preenchido à medida que os dados da seção vão sendo digitados, e é composto do primeiro e último nome do paciente e dos demais dados dos campos anteriores a fim de criar um identificador que ao ser visualizado ajudará o Médico Regulador a compreender o perfil da vítima, além de otimizar espaço ao possibilitar a fácil visualização de todas essas informações durante o restante da regulação utilizando o menos espaço;

D. Utilização do espaço livre logo abaixo dos dados do paciente para criação da Lista de paciente onde ficarão à mostra os pacientes incluídos na ocorrência.

Além do mais, um protótipo da interface Avaliação/Orientação Médica que complementa os dados sobre o paciente foi elaborado, com as melhorias na interface destacadas na Figura 6.

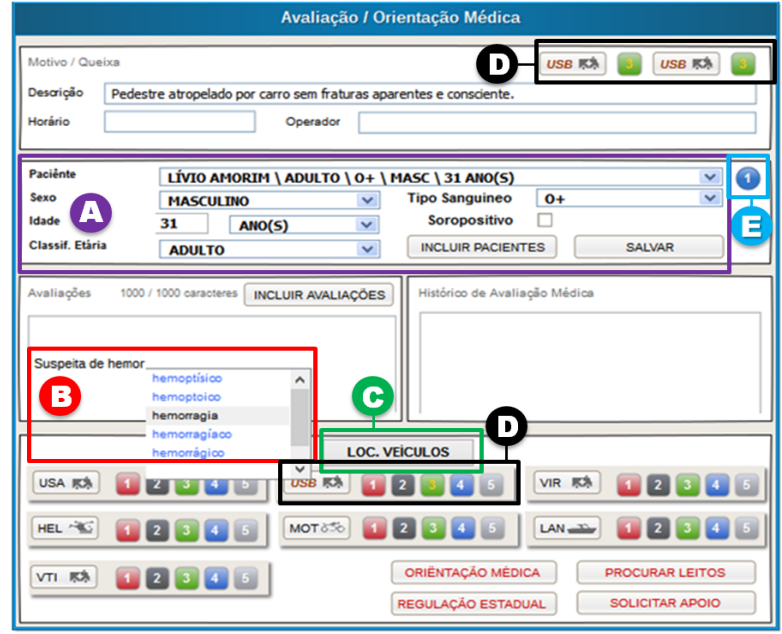

Figura 6 - Protótipo da interface Avaliação / Orientação Médica

A. Reorganização das informações básicas do paciente seguindo a estrutura dos dados de identificação na aba Paciente;

B. Implementação de autocomplete ao processo de digitação a fim reduzir o tempo para inserção da avaliação e minimizar o esforço mental do Médico Regulador com questões como ortografia e dúvidas de vocabulário;

C. Inserção do botão LOC. VEÍCULOS que carrega a nova tela Localização de Veículos / Ocorrências onde estão disponíveis as localizações de todas as unidades de atendimento móvel cadastradas e rastreáveis em um mapa virtual da região e caso tenha sido possível a obtenção do Geocoding para a Localização da ocorrência, a mesma também será visualizada na tela Localização de Veículos / Ocorrências, conforme mostrado na próximo protótipo de tela;

D. Ao selecionar um determinado tipo de unidade veicular de atendimento para um paciente e o respectivo grau de risco deste a mesma ficará em destaque no painel, podendo ser marcada novamente caso exista a necessidade de encaminhar mais uma unidade do mesmo tipo, e a ficha ganhará um marcador correspondente para cada unidade no canto superior direito da tela;

E. Indicador com o número de pacientes ainda não avaliados pela primeira vez ao lado do campo Paciente. O processo de avaliação só pode ser finalizado quando não houver mais nenhum paciente para ser avaliado. 
Seguindo o desenho metodológico da pesquisa, todas as propostas e sugestões apresentadas nos protótipos de interfaces ilustrados acima foram resubmetidas para validação junto aos usuários, sendo empreendidas novas entrevistas com os atores envolvidos no processo interno de atendimento de chamadas de emergência do SAMU. No desenvolvimento dos protótipos buscou-se oferecer alternativas que visassem o tratamento de fatores que poderiam atrapalhar a aquisição da consciência situacional por parte dos agentes envolvidos na utilização do sistema, conforme preconiza Endsley (1999). Estes fatores estão resumidos no quadro a seguir.

\begin{tabular}{|c|c|c|c|c|c|c|}
\hline \multicolumn{7}{|c|}{ Protótipo para a Interface Solicitante } \\
\hline Sugestão & $\begin{array}{l}\text { Gargalo de } \\
\text { atenção }\end{array}$ & $\begin{array}{l}\text { Limitação de } \\
\text { memória }\end{array}$ & Stress & $\begin{array}{c}\text { Excesso de } \\
\text { dados }\end{array}$ & $\begin{array}{c}\text { Saliências } \\
\text { mal inseridas }\end{array}$ & $\begin{array}{c}\text { Complexi- } \\
\text { dade do } \\
\text { sistema }\end{array}$ \\
\hline A & $\mathrm{X}$ & $\mathrm{X}$ & & & & \\
\hline B & & & & & $\mathrm{X}$ & $\mathrm{X}$ \\
\hline $\mathrm{C}$ & & $\mathrm{X}$ & & $\mathrm{X}$ & & \\
\hline $\mathrm{D}$ & & $\mathrm{X}$ & $\mathrm{X}$ & & & \\
\hline $\mathrm{E}$ & & $\mathrm{X}$ & $\mathrm{X}$ & & & \\
\hline $\mathrm{F}$ & & & & $\mathrm{X}$ & & \\
\hline G & & & & $\mathrm{X}$ & & \\
\hline $\mathrm{H}$ & $\mathrm{X}$ & & & & $\mathrm{X}$ & \\
\hline I & $\mathrm{X}$ & & & & & $\mathrm{X}$ \\
\hline \multicolumn{7}{|c|}{ Protótipo para a interface Paciente } \\
\hline Sugestão & $\begin{array}{l}\text { Gargalo de } \\
\text { atenção }\end{array}$ & $\begin{array}{l}\text { Limitação de } \\
\text { memória }\end{array}$ & Stress & $\begin{array}{l}\text { Excesso de } \\
\text { dados }\end{array}$ & $\begin{array}{c}\text { Saliências } \\
\text { mal inseridas }\end{array}$ & $\begin{array}{c}\text { Complexi- } \\
\text { dade do } \\
\text { sistema }\end{array}$ \\
\hline A & $\mathrm{X}$ & $\mathrm{X}$ & & $\mathrm{X}$ & & \\
\hline B & & $\mathrm{X}$ & $\mathrm{X}$ & & & \\
\hline $\mathrm{C}$ & & $\mathrm{X}$ & $\mathrm{X}$ & & & \\
\hline
\end{tabular}




\begin{tabular}{|c|c|c|c|c|c|c|}
\hline \multicolumn{7}{|c|}{ Protótipo para a interface Avaliação/Orientação Médica } \\
\hline Sugestão & $\begin{array}{c}\text { Gargalo de } \\
\text { atenção }\end{array}$ & $\begin{array}{c}\text { Limitação de } \\
\text { memória }\end{array}$ & Stress & $\begin{array}{c}\text { Excesso de } \\
\text { dados }\end{array}$ & $\begin{array}{c}\text { Saliências } \\
\text { mal inseridas }\end{array}$ & $\begin{array}{c}\text { Complexi- } \\
\text { dade do } \\
\text { sistema }\end{array}$ \\
\hline $\mathrm{A}$ & $\mathrm{X}$ & $\mathrm{X}$ & $\mathrm{X}$ & & & \\
\hline $\mathrm{B}$ & & $\mathrm{X}$ & $\mathrm{X}$ & & & \\
\hline $\mathrm{C}$ & & $\mathrm{X}$ & $\mathrm{X}$ & & & \\
\hline $\mathrm{D}$ & & $\mathrm{X}$ & $\mathrm{X}$ & & & \\
\hline $\mathrm{E}$ & $\mathrm{X}$ & $\mathrm{X}$ & $\mathrm{X}$ & & & \\
\hline
\end{tabular}

\section{Quadro 3 - Relação entre as sugestões para a interface e o tratamento de fatores que dificultavam a aquisição da consciência situacional Fonte: Dados da pesquisa}

Sendo assim, com relação aos níveis de alcance da consciência situacional expostos no Quadro 3, foi possível observar que das 30 (trinta) sugestões apresentadas no total, 14 (quatorze) delas contribuíram para a melhoria do nível de percepção, 15 (quinze) foram relevantes para o nível da compreensão do sistema e 6 (seis) beneficiaram também o nível de previsão. Estes dados apontam que através do tratamento desses fatores, que poderiam atrapalhar a aquisição da consciência situacional do sistema, os protótipos de interfaces apresentados pela pesquisa alcançaram melhorias nos níveis de percepção, compreensão e previsão de SA, acarretando numa aceitação positiva por parte dos usuários dos protótipos.

\section{Conclusões}

O intuito desta pesquisa foi empreender uma análise qualitativa, através do viés da consciência situacional, acerca dos impactos das interfaces dos sistemas de informação em saúde nas tarefas de trabalho dos usuários responsáveis pela entrada de dados dos atendimentos de emergência do SAMU. Foram sugeridas soluções aprimoradas de protótipos de interfaces que objetivaram minimizar os principais aspectos negativos para alcance da consciência situacional no serviço de atendimento, que foram: gargalo de atenção, limitação de memória, stress dos usuários, excesso de dados, saliências mal inseridas e complexidade do sistema.

O estudo buscou comprovar que a aplicação do conceito de consciência situacional em interfaces de sistemas e sua aquisição pelos sujeitos envolvidos pode ser essencial para uma realização mais eficiente das tarefas no processo de atendimento do SAMU, principalmente, na utilização de um software em um ambiente de trabalho sob pressão, que exige decisões rápidas e cruciais dos usuários. Os protótipos de IU construídos nesta pesquisa podem tanto serem aproveitados como sugestões para 
melhoria da interface do sistema principal já implantado, como também podem servir de base para o desenvolvimento de sistemas de apoio integrados ao e-SUS SAMU.

Uma limitação do estudo foi que, inicialmente, desejava-se validar a análise da consciência situacional dos usuários através da metodologia SAGAT por completo [Endsley e Jones 2016], que consistiria em adotar uma pergunta para os usuários em períodos aleatórios e em intervalos mínimos de 1 (um) minutos entre elas, sendo feita após o congelamento da tela da interface, fornecendo opções categóricas para minimizar o esforço mental do sujeito. Entretanto, esbarrou-se na dificuldade de reunir um grupo composto por cada ator do processo, haja vista a impossibilidade de deslocar vários profissionais de sua função em um ambiente de trabalho dinâmico e crítico, tal como o do SAMU. Como trabalho futuro, vislumbra-se avançar para uma etapa quantitativa do estudo, que será a emulação das tarefas no ambiente de trabalho seguindo a SAGAT, simulando um caso de uso a partir dos protótipos das interfaces desenvolvidas e, então, mensurar o nível de consciência alcançado, assim como implementar as funcionalidades para os protótipos apresentados neste estudo.

\section{Referências}

Abib, G.; Hoppen, N.; Hayashi Junior, P. Observação participante em estudos de administração da informação no Brasil. Rev. adm. empres. [online]. 2013, vol.53, n.6 [cited 2019-04-19], pp.604-616. Disponível em: $<$ http://www.scielo.br/scielo.php?script=sci_arttext\&pid=S0034$75902013000600008 \& \operatorname{lng}=$ en\&nrm=iso $>$ ISSN http://dx.doi.org/10.1590/S0034-759020130608.

0034-7590.

Baratto, G. Consciência Situacional no Treinamento de Voo por Instrumentos Inicial. Curitiba. 2011. Disponível em: <http://tcconline.utp.br/wpcontent/uploads/2013/06/CONSCIENCIA-SITUACIONAL-NO-

TREINAMENTO.pdf>. Acesso em: Mar. 2019.

Cabral, A.; Souza, W.; Lima, M. Serviço de Atendimento Móvel de Urgência: Um observatório dos acidentes de transportes terrestre em nível local. Revista Brasileira de Epidemiologia. 14(1): 3-14. 2011.

Endsley, M. R. Toward a Theory of Situation Awareness in Dynamic Systems. Human Factors Journal. 37(1), 32-64, 1995. Disponível em: $<$ http://apps.usd.edu/coglab/schieber/docs/Endsley1995a.pdf>. Acesso em: Dez. 2018.

Endsley, M. R. Situation Awareness In Aviations Systems. Handbook of Aviation Human Factors. Mahwah, NJ, 257 - 276, 1999. Disponível em: $<$ http://www.pacdeff.com/pdfs/AviationSA-Endsley\%201999.pdf>. Acesso em: Dez. 2018 .

Endsley, M. R.; Jones, D. G. Designing for situation awareness: An approach to usercentered design. 2016. CRC Press, USA.

Ferreira, L. Desenvolvimento de Interface de Usuário para a Melhoria da Consciência Situacional em Sistemas de Tomada de Decisão Militar. UNIVEM/F.E.E.S.R.. Marília, 2014.

Disponível 
em:<http://aberto.univem.edu.br/bitstream/handle/11077/1022/Lucas\%20Cesar\%20F erreira.pdf? sequence=1>. Acesso em: Mar 2019.

Henriqson, E.; júnior, G. C. C.; Saurin, T. A.; Amaral, F. G. Consciência Situacional, tomada de decisão e modos de controle cognitivo em ambientes complexos. Produção, v. 19, n. 3, p. 433-444, 2009. Disponível em: <http://www.scielo.br/pdf/prod/v19n3/02.pdf>. Acesso em: Mar. 2019.

Nazir, S.; Colombo, S.; Manca, D. The Role of Situation Awareness for the Operators of Process Industry. Chemical Engineering Transactions. Politecnico di Milano, Milano, Italy, v. 26, 2002. Disponível em: <http://www.aidic.it/cet/12/26/051.pdf>. Acesso em: Mar. 2019.

Oliveira, N.; Rodrigues, F.; Souza, J.; Botega, L.; Araújo, R. Interface de Usuários para o Enriquecimento da Consciência Situacional em Sistemas de Gerenciamento de Emergência. Journal on Advances in Theoretical and Applied Informatics - JADI, Marilia, v.1, n. 1, p. $60 \quad$ - 71, 2015. Disponível em: $<\mathrm{https}$ //www.researchgate.net/publication/295547138_Interface_de_Usuarios_para_ o_Enriquecimento_da_Consciencia_Situacional_em_Sistemas_de_Gerenciamento_d e_Emergencia>. Acesso em: Dez. 2018.

Oliveira, N,; Botega, L.; Berti, C.; Campos, M.; Neris, V.; Araújo, R. Visualização de Incertezas para a Melhoria da Consciência Situacional em Sistemas de Chamadas de Emergência. In: XIII Simpósio Brasileiro Sobre Fatores Humanos, Foz do Iguaçu, 2014. Disponível

em: $<$ https://www.researchgate.net/publication/268523791_Visualizacao_de_Incertezas_ para_a_Melhoria_da_Consciencia_Situacional_em_Sistemas_de_Chamadas_de_Em ergencia>. Acesso em: Dez. 2018.

Onal, E.; Craddock, C.; Endsley, R. From Theory To Practice: How Designing For Situation Awareness Can Transform Confusing, Overload Shovel Operator Interfaces, Reduce Costs, and Increase Safety, pp. 1517-1525. Proceedings of the 30th ISARC, Montréal, Canada, 2013.

Orlikowski, W. J., and Baroudi, J. J. Studying Information Technology in Organizations: Research Approaches and Assumptions, Information Systems Research (2:1), 1991, pp. 1-28.

Pew, R.; Mavor, A.; Modeling Human and Organizational Behavior. Application To Military Simulations. Cap. 7, 172-199. National Academy Press. Washington, D.C. 1998. Disponível em: <https://www.nap.edu/read/6173/chapter/9>. Acesso em: Dez. 2018.

Silva, A.; Lacerda, M.; Santos, N.; Fialho, F.; Netto, M. Consciência da situação em equipes transdisciplinares. Ciências \& Cognição. Vol. 17 (2), 115-134, 2012. Disponível em: <http://pepsic.bvsalud.org/scielo.php?script=sci_arttext\&pid=S180658212012000200010>. Acesso em: Dez. 2018.

Velagapudi, P.; Owens, S.; Scerri, P.; Sycara, K. Environmental Factors Affecting Situation Awareness in Unmanned Aerial Vehicles. 2009. Carnegie Mellon University, Pittsburgh, PA, 15213, USA. 